\author{
Dhanesh G. Mohan ${ }^{1 *}$, Jacek Tomków ${ }^{2}$, S. Gopi ${ }^{3}$ \\ ${ }^{1}$ Institute of Materials Joining, Shandong University, Jinan, China \\ ${ }^{2}$ Faculty of Mechanical Engineering and Ship Technology, Gdańsk University of Technology, \\ Poland \\ ${ }^{3}$ Department of Production Engineering, Government College of Technology, Coimbatore, \\ India \\ *dhaneshgm@gmail.com
}

\title{
INDUCTION ASSISTED HYBRID FRICTION STIR WELDING OF DISSIMILAR MATERIALS AA5052 ALUMINIUM ALLOY AND X12Cr13 STAINLESS STEEL
}

\begin{abstract}
This research aimed to study the induction in-situ heated hybrid friction stir welding (IAFSW) method to join AA5052 aluminium alloy with $\mathrm{X} 12 \mathrm{Cr} 13$ stainless steel (SS) to enhance joint strength. The potency of this method on the mechanical properties and microstructural characterizations were also investigated. The results show that the transverse tensile strength gained was $94 \%$ of the AA5052 base metal that is $229.5 \mathrm{MPa}$. This superior strength was achieved due to the annealing that happened to the AA 5052 region and elevated plastic flow in the weld zone by the in-situ induction heating, which resulted in the elongation of the weld region. The microstructure characterization indicates that a refined grain structure was gained in the nugget zone without defects.
\end{abstract}

Keywords: Induction heating; friction stir welding; dissimilar joints; aluminium alloys; stainless steel

\section{INTRODUCTION}

In this current scenario, the requirement for lightweight structures for automobiles and aerospace is relatively high. This leads to the joining of dissimilar metals with different mechanical as well as chemical properties. Lightweight metals like aluminium and magnesium are widely used to reduce the structure's weight and enhance the corrosion resistance properties. In order to encompass light metals to high strength alloys like stainless steel (SS), a new welding method is required, and the existing fusion welding is not adequate to produce such joints due to the formation of intermetallic compounds and thereby reduction of joint strength [1]. Friction stir welding (FSW) is the joining method of this decade, and it is successfully employed for light metals like $\mathrm{Al}$ and its alloys. This method also enhances the weldability of the joints by reducing the heat-affected zone. This method's prime advantage is its solid-state welding method, which does not melt the parent metal and joins the metals in the plastic stage itself by a specially designed tool [2]. Moreover, intermetallic phase 
formation got reduced while employing FSW. Conversely, the joining of stainless with aluminium by using FSW is quite limited due to its different physical properties.

The different properties of the AA 5052 and X12Cr13 SS, such as melting point, material flow, and grain structure, led to the tool wear in FSW and resulted in poor joint strength. Abd Elnabi et al. [3] joined and studied the effect of FSW in 1050 pure aluminium and annealed low carbon steel joining, the result shows that the maximum strength obtained is $79 \mathrm{MPa}$ which is $54.8 \%$ compared to the strength of 1050 pure aluminium. While examining the fractography of this specimen, it reveals that the tensile failure is due to the scattered steel fragments in the weld zone, which is happened due to the improper plasticization and material flow in the weld zone. Anaman et al. [4] studied the microstructure formation and mechanical properties of 5052-H32 aluminium and DP 1200 steel alloys. In the stir zone, three significantly different layers were gained. The top layer consists of an aluminium matrix reinforced with steel fragments; the second layer consists of Fe single bond $\mathrm{Al}$ solid solutions and a couple of IMCs, like $\mathrm{Fe}_{2} \mathrm{Al}_{3}, \mathrm{FeAl}_{2}$ and $\mathrm{FeAl}$, and the third consist of distorted steel. The top layer exhibited superior microhardness due to the presence of scattered steel particles. Compared to the first and third layers, the second layer shows better corrosion resistance due to the proper amalgamation of aluminium and steel in that region. The third layer shows higher mechanical properties but is prone to corrosion. Wang et al. [5] butt joined aluminium alloy 5083-H116 and steel sheets HSLA-65 by friction stir welding and examined its weld properties. Their studies show that tensile strength of $289 \mathrm{MPa}$ was achieved, that is, the $90 \%$ strength of the base aluminium alloy. Also, stress concentration and brittle IMC at the boundary between weld nugget wear were visible, and the steel region was directed to crack initiation and propagation.

Joo [6] successfully joined AZ31B magnesium alloy and SS400 mild steel using gas tungsten arc-friction stir welding (GTA-FSW). The GTA preheating source was concentrations on the SS400 mild steel due to the lesser meting property of magnesium alloy. Finally, the results gained by GTAFSW was compared with conventional FSW. The results reveal that GTA-FSW exhibits a superior joint strength of 237 MPA, while the conventional joint exhibits a strength of $226 \mathrm{MPa}$ [7]. This higher tensile strength gained by the GTA-FSW resulted from the enriched plastic flow achieved by the GTA preheating and the partial annealing of the magnesium alloy.

With laser-assisted friction stir welding (LAFSW), DC04 steel was welded by Campanelli S L et al. [8]. The results reveal that the laser beam reduces the residual stress, and improves the microhardness of the weld zone. The preheating by the laser influenced the nugget zone drastically a waste structural transformation was visible over there [9]. This preheating by laser helps the joints to attain an improved elongation without compromising the mechanical properties. Nevertheless, the microhardness gained in the preheated region is superior to the other areas in the weldment.

These results clearly portraited that the joint strength is highly influenced by the plasticization of the weld region and proper heat distribution. Moreover, the frictional heat produced by the tool is not sufficient to plasticize the SS and cause tool fracture and wear. These limitations are overcome by adopting an in-situ induction heating method. Thus induction heating can only heat ferromagnetic materials; while employing induction heating, only the X12Cr13 SS region will get heated [10]. The plasticization in the AA5052 region is by the heat conducted from the steel region and by the frictional heat generated by the FSW tool. Therefore, the problems encountered by the previous work can be eliminated by employing an induction in-situ heating method. Besides, this method enhances the material flow in the weld zone, thereby achieving a fine grain structure. 
The current study carries out by induction in-situ heated hybrid FSW (IAFSW) to enhance the joint strength of AA5052 (aluminium alloy) with X12Cr13 SS by augmenting the material flow, which is initiated by the in-situ heating of the SS surface by induction heating.

\section{EXPERIMENTAL}

The plates' dimensions (AA5052 and X12Cr13 SS) used for this experiment have $3 \mathrm{~mm}$ thickness, $75 \mathrm{~mm}$ width and $100 \mathrm{~mm}$ length [11]. The mechanical properties and chemical compositions of the base metals provided in the material certificate given by the supplier were presented in Table 1.

Table 1. Chemical compositions and mechanical properties of alloys

\begin{tabular}{|c|c|c|c|c|c|c|c|c|}
\hline \multirow{2}{*}{$\begin{array}{c}\text { Material } \\
\text { AA5052 }\end{array}$} & \multicolumn{8}{|c|}{ Chemical composition (Wt.\%) } \\
\hline & Mn & $\mathrm{Fe}$ & $\mathrm{Cu}$ & $\mathrm{Mg}$ & $\mathrm{Si}$ & $\mathrm{Zn}$ & $\mathrm{Cr}$ & $\mathrm{Al}$ \\
\hline & 0.10 & 0.37 & 0.08 & 2.65 & 0.22 & 0.08 & 0.32 & Balance \\
\hline & \multicolumn{8}{|c|}{ Mechanical Properties } \\
\hline & \multicolumn{2}{|c|}{ Tensile strength(MPa) } & \multicolumn{2}{|c|}{ Elongation(\%) } & \multicolumn{2}{|c|}{$\operatorname{Density}\left(\mathrm{g} / \mathrm{cm}^{3}\right)$} & \multicolumn{2}{|c|}{ Melting point $\left({ }^{\circ} \mathrm{C}\right)$} \\
\hline & \multicolumn{2}{|c|}{245} & \multicolumn{2}{|c|}{12} & \multicolumn{2}{|c|}{2.68} & \multicolumn{2}{|c|}{600} \\
\hline Material & \multicolumn{8}{|c|}{ Chemical composition (Wt.\%) } \\
\hline \multirow[t]{5}{*}{$\mathrm{X} 12 \mathrm{Cr} 13 \mathrm{SS}$} & $\mathrm{C}$ & $\mathrm{Mn}$ & $\mathrm{Si}$ & $\mathrm{P}$ & $S$ & $\mathrm{Cr}$ & $\mathrm{Ni}$ & $\mathrm{Fe}$ \\
\hline & 0.14 & 1.00 & 0.95 & 0.03 & 0.02 & 13.4 & 0.71 & Balance \\
\hline & \multicolumn{8}{|c|}{ Mechanical Properties } \\
\hline & \multicolumn{2}{|c|}{ Tensile strength $(\mathrm{MPa})$} & \multicolumn{2}{|c|}{ Elongation $(\%)$} & \multicolumn{2}{|c|}{$\operatorname{Density}\left(\mathrm{g} / \mathrm{cm}^{3}\right)$} & \multicolumn{2}{|c|}{ Melting point $\left({ }^{\circ} \mathrm{C}\right)$} \\
\hline & \multicolumn{2}{|c|}{450} & \multicolumn{2}{|c|}{29.5} & \multicolumn{2}{|c|}{7.80} & \multicolumn{2}{|c|}{1520} \\
\hline
\end{tabular}

Figure 1 shows the induction heating coil fabricated using $2 \mathrm{~mm}$ hollow copper wire, having a coil diameter of $20 \mathrm{~mm}$, and insulated using Teflon tapes. While performing the induction heating process, cool water will circulate inside the coil to prevent overheating.

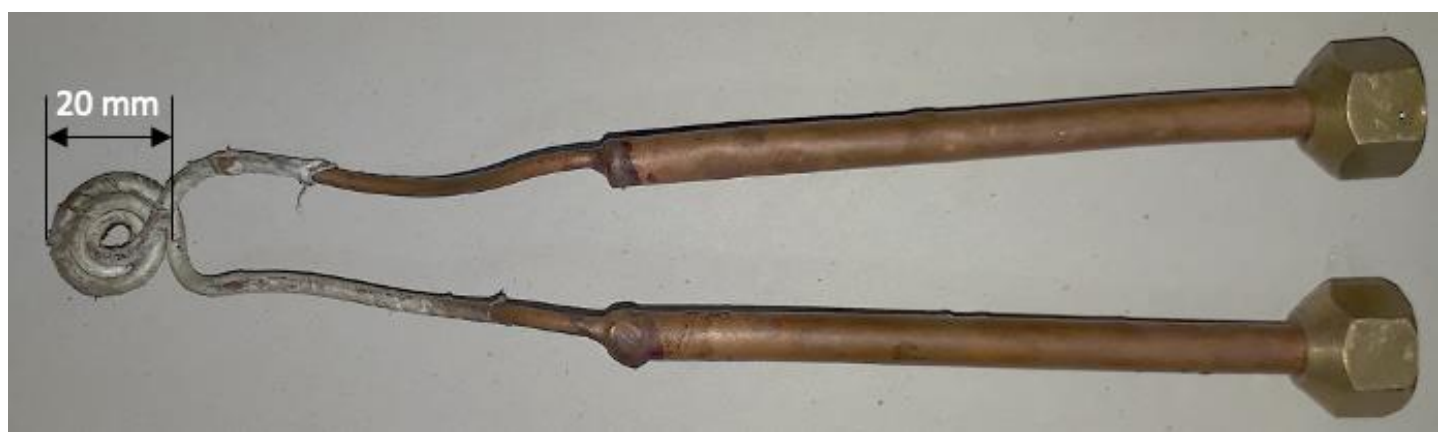

Fig. 1. Induction heating coil 
Figure 2a shows the induction in-situ heating coil leading FSW tool made of sintered tungsten carbide - cobalt. A hexagonal profiled tool pin with a flat shoulder was adopted for this experiment $[12,13]$. Figure $2 \mathrm{~b}$ shows the schematical image of the tool with dimensions. The dimensions of the tool are $20 \mathrm{~mm}$ shoulder diameter, pin diameter of $5.6 \mathrm{~mm}$, pin length of $2.5 \mathrm{~mm}$.

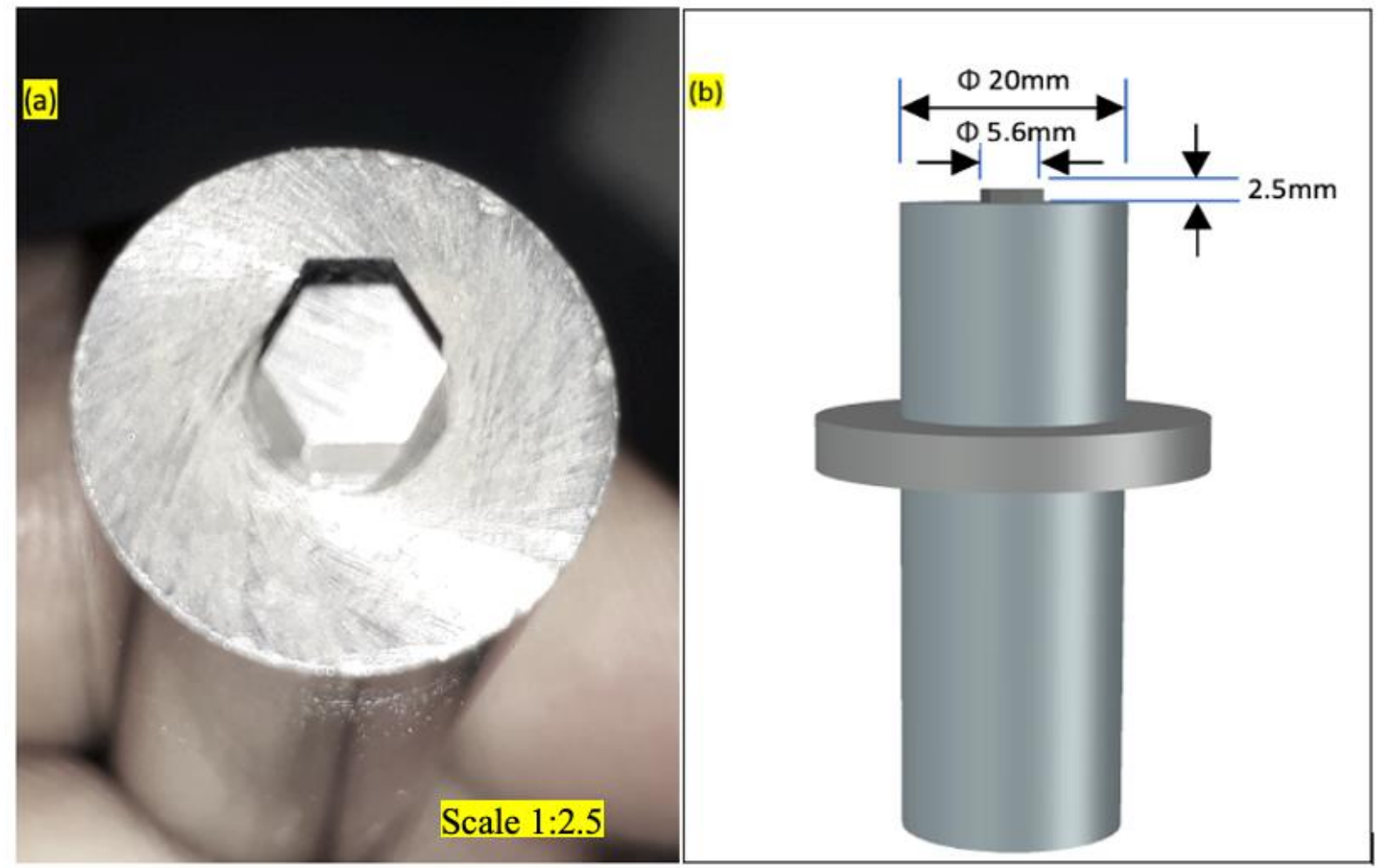

Fig. 2. (a) IAFSW tool, (b) Schematic representation of the tool with dimensions

While performing the experiment, the IAFSW tool adopted a tilt angle of $3^{\circ}$ and set the tool offset of $0.5 \mathrm{~mm}$ along the $\mathrm{X} 12 \mathrm{Cr} 13 \mathrm{SS}$ side. Figure 3 shows the schematic representation of the IAFSW. For this study, the X12Cr13 SS was placed at the advancing side of the butt configuration, and the AA5052 was placed at the retreating side, respectively [14-16]. IAFSW was executed at the following parameter ranges, the tool rotation speed of 600, 750 and $900 \mathrm{rpm}$, welding speed $53 \mathrm{~mm} / \mathrm{min}$, plunge depth $0.58 \mathrm{~mm}$, induction power $55 \mathrm{~W}$, which produce a temperature of $486{ }^{\circ} \mathrm{C}$, and a standoff distance from the tool centre to induction coil centre of $35 \mathrm{~mm}$.

To examine the mechanical properties of the weldments, tensile tests and Vickers microhardness tests were conducted. As per the ASTM E8M-04 standard, the tensile specimens were prepared, and the tensile test was conducted at a load of $100 \mathrm{kN}$ with 2 $\mathrm{mm} / \mathrm{min}$ ram speed. The microhardness tests were conducted per ASTM E384 standards (with the testing method HV10) on an HV-110 model Mitutoyo Micro Vickers hardness testing machine using a test forces scale from $0.5-35 \mathrm{~kg}$. The tensile specimen's schematic representation with dimensions is given in Figure 4a, and IAFSW tensile specimen is shown in Figure 4b. At a load of $0.5 \mathrm{~N}$ and a dwell time of $10 \mathrm{~s}$, the microhardness test was conducted along the transverse cross-section of the weld zone [17]. The microstructure analysis and elemental characterizations were performed with an optical microscope and scanning electron microscope (SEM). 


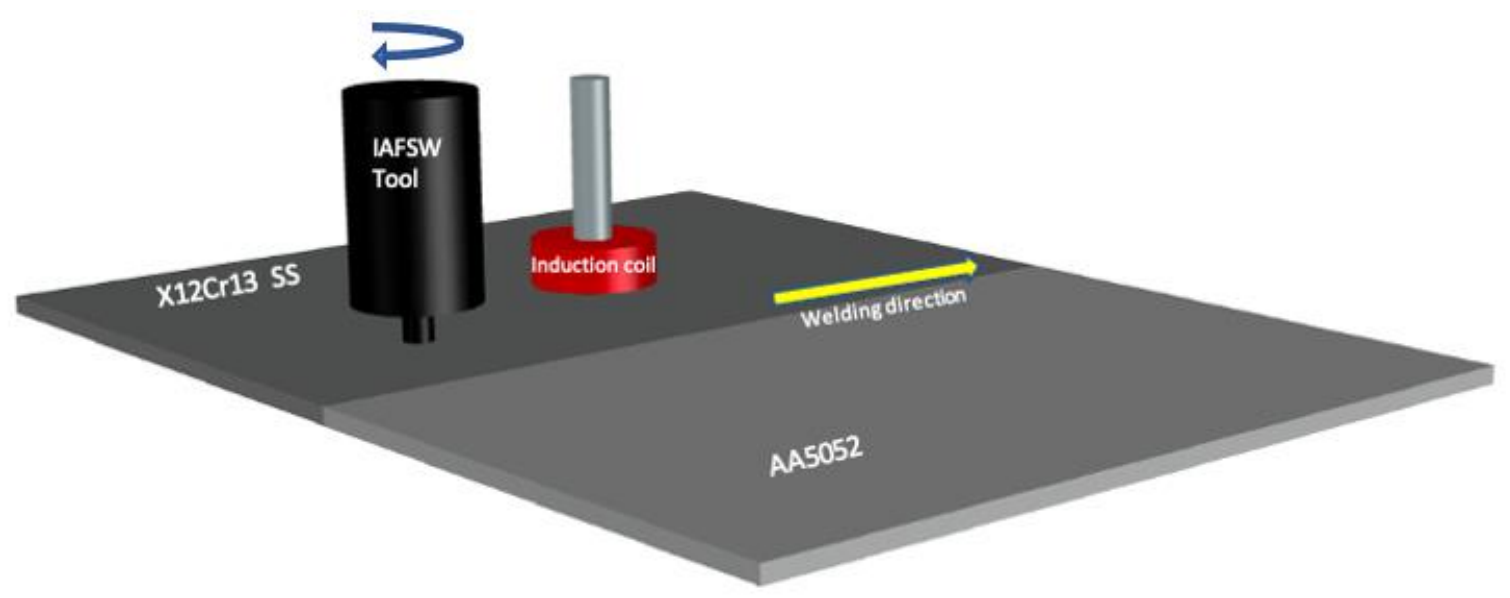

Fig. 3. Schematic representation of IAFSW

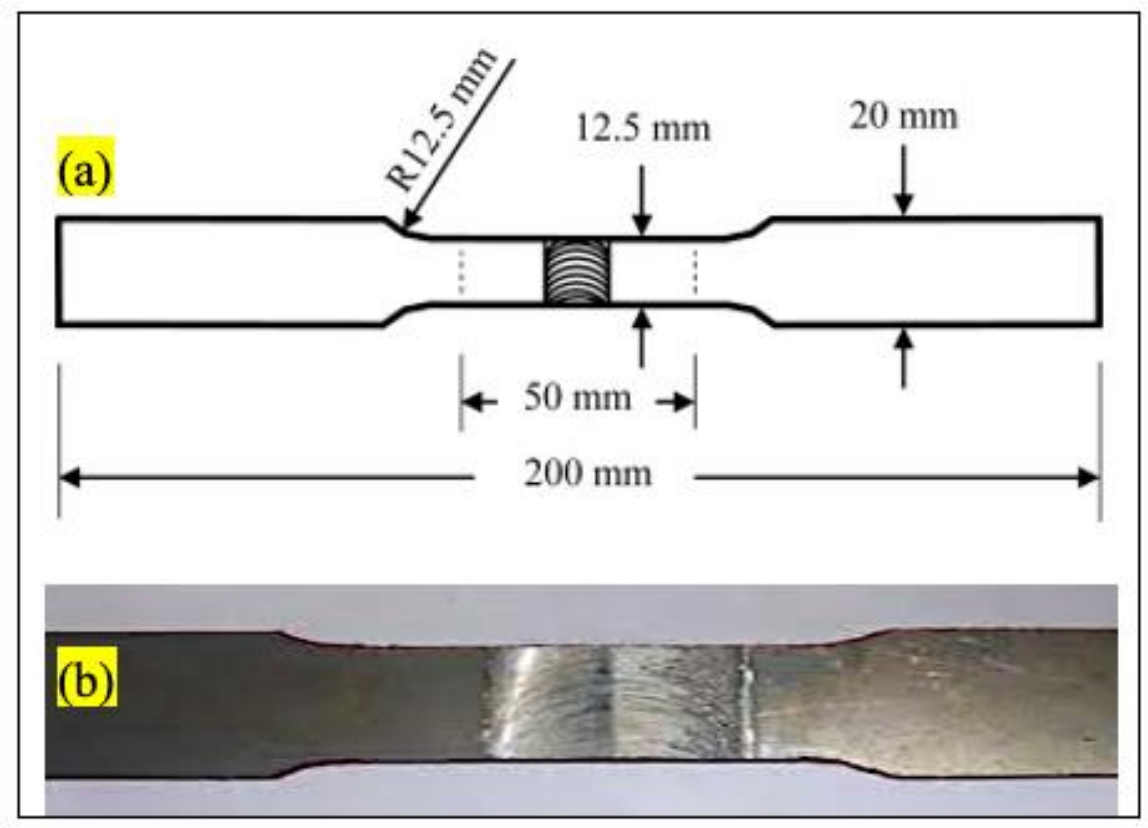

Fig. 4. (a) Schematic representation of tensile specimen with dimensions (b) IAFSW tensile specimen

\section{RESULTS AND DISCUSSIONS}

\section{Surface Morphology and Nugget Cross-section of IAFSW joint}

The surface morphology and nugget cross-section of (AA5052 area and X12Cr13 SS area) IAFSW joints prepared using a rotational speed of $750 \mathrm{rpm}$ are given in Figure 5. The nugget cross-section was polished using 200 to 2000 grade emery papers and etched for 1 min, using Keller's reagent $\left(2.5 \mathrm{~mL} \mathrm{HNO}_{3}+1.5 \mathrm{~mL} \mathrm{HCl}+1.0 \mathrm{~mL} \mathrm{HF}+95 \mathrm{~mL} \mathrm{H}_{2} \mathrm{O}\right)$. 


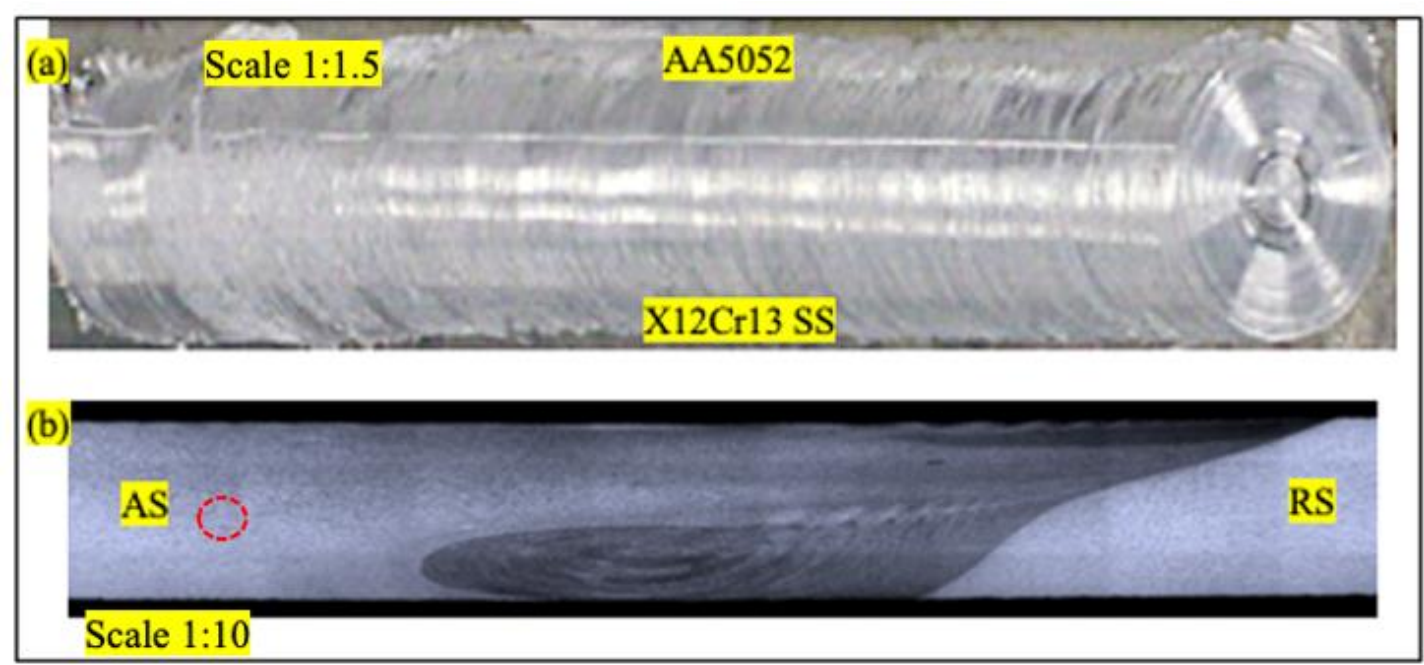

Fig. 5. (a) IAFSW surface morphology, (b) Nugget cross-section of AA5052 and X12Cr13 SS

The surface morphology and the nugget cross-sections of the IAFSW specimen prepared using rotational speed $750 \mathrm{rpm}$ without any morphological or cross-sectional defects. Meanwhile, the weldment fabricated using $600 \mathrm{rpm}$ exhibits some voids due to the IAFSW tool pin's sintering effect and cause the formation of coarse X12Cr13 SS particles. Also, the AA5952 particles were located in a distance from the surface of SS [18,19]. The insufficient tool rotation speed $(600 \mathrm{rpm})$ cause the settling of large X12Cr13 SS particles in the retreating side of the weldment and thereby reduces the joint strength. Also, this leads to the propagation of fracture along with the bimetallic interface in the nugget zone [20]. The lack of material movement is visible in the joint produced by $600 \mathrm{rpm}$ due to the insufficient heat generated by the tool.

Conversely, the joint produced at $900 \mathrm{rpm}$ shows disseminated flimsy X12Cr13 SS particles in the nugget zone due to the excessive heat generated by the synergic effect of the IAFSW tool and induction heater [21]. Moreover, the excessive stirring in the weld zone drags the metals from the nugget zone and cause worm defects. A defect-free joint was fabricated at $750 \mathrm{rpm}$ from the above findings, and this tool rotation speed is accurate for AA5052 and X12Cr13 SS combinations.

\section{Mechanical Properties of IAFSW joints}

Figure 6 shows the fractured area of the IAFSW specimen prepared at a tool rotation speed of $750 \mathrm{rpm}$. The failure has happened at the heat-affected zone of the AA5052 region. Figure 7 shows the tensile strength graph for all three specimens, and Table 2 shows the tensile strengths of the specimens with respected tool rotation speeds. The specimen prepared by $750 \mathrm{rpm}$ provides the highest transverse tensile strength of $229.5 \mathrm{MPa}$, which is $94 \%$ of the AA5052 base plate.

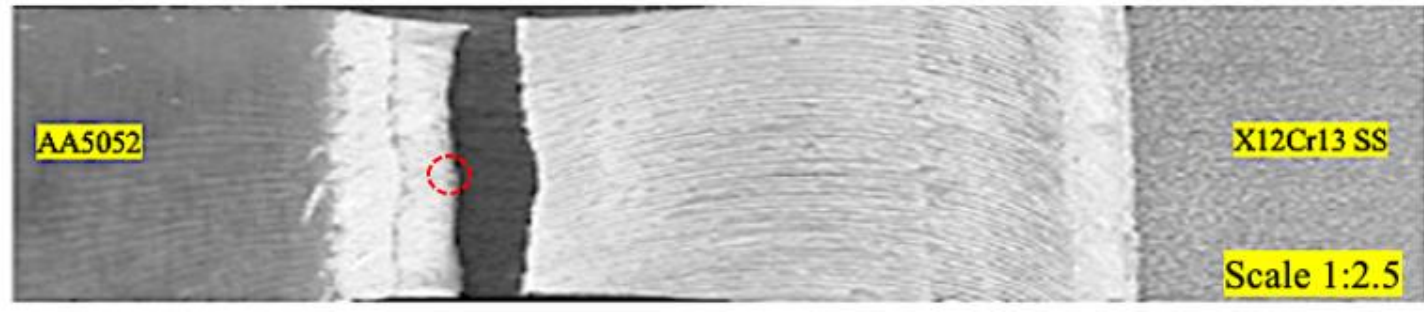

Fig. 6. Fractured IAFSW specimen 


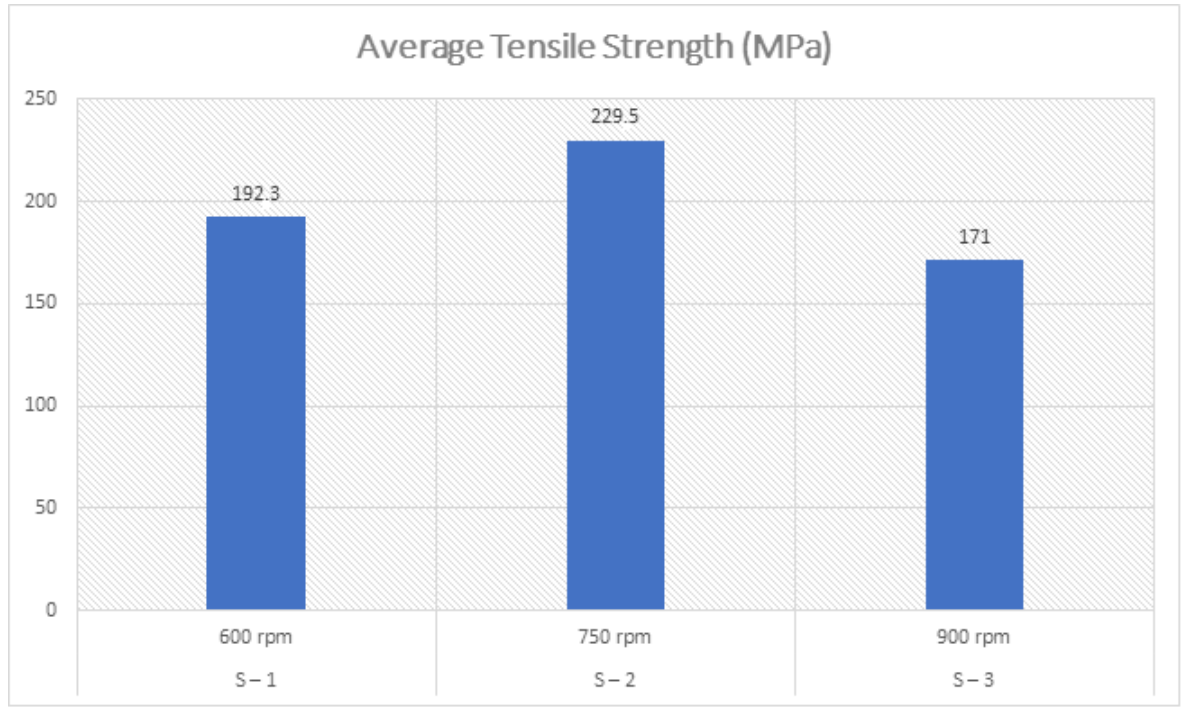

Fig. 7. Average tensile strength for three specimens

Table 2. Tensile test results with respected tool rotation speed

\begin{tabular}{ccc}
\hline $\begin{array}{c}\text { Specimen } \\
\text { Number }\end{array}$ & $\begin{array}{c}\text { Tool rotation speed } \\
(\mathrm{rpm})\end{array}$ & $\begin{array}{c}\text { Average Tensile } \\
\text { Strength (MPa) }\end{array}$ \\
\hline $\mathrm{S}-1$ & $600 \mathrm{rpm}$ & 192.3 \\
\hline $\mathrm{S}-2$ & $750 \mathrm{rpm}$ & 229.5 \\
\hline $\mathrm{S}-3$ & $900 \mathrm{rpm}$ & 171.0 \\
\hline
\end{tabular}

The average tensile strength achieved by the first specimen is $192.3 \mathrm{MPa}$, which is 75.45 $\%$ of the tensile strength of AA5052; where the third specimen fabricated at $900 \mathrm{rpm}$ exhibits even lesser average tensile strength than the first and second specimens, which is $171.0 \mathrm{MPa}$, that is $67.06 \%$ strength of aluminium alloy base metal. In the first specimen, the fracture has happened at the bimetallic interface at the aluminium region in the thermomechanical affected zone [22]. The heat generated by the $600 \mathrm{rpm}$ tool rotation did not plasticize the weld zone well. It resulted in the segregation of coarse steel particles in the thermomechanical affected zone, thereby reduced the joint's strength. In the third specimen, which is fabricated by 900 $\mathrm{rpm}$ tool rotation speed, the excessive tool rotation and the induction heat from the coil overplasticize the weld zone, resulting in the dragging of metal from the nugget zone and forms tunnel defects. Due to these tunnel defects, the strength of the joints got reduced. The second specimen's tensile strength is enhanced by generating the optimum temperature by the tool and the plasticization done by the induction heater. It has already been proven that in-situ heating or preheating by an additional heating source will enhance the tensile strength of the joints.

Figure 6 reveals the ductile fracture behaviour of the IAFSW joint. In Figures 5 and 6 , a small red circle is inscribed, at that region, the fracture was prolonged, and the fractography was taken. The in-situ heating and the heat generated by the IAFSW tool enhance the material flow and lead to the partial annealing on the X12Cr13 SS area, which considerably improves the elongation and produces a sound joint with improved tensile strength. Besides, specimens one and three exhibit brittle fracture due to insufficient and over material flows, respectively, 
and show some unmixed bimetallic structure [23]. Fractography image of IAFSW tensile specimen performed by scanning electron microscope (SEM) is showed in Figure 8.

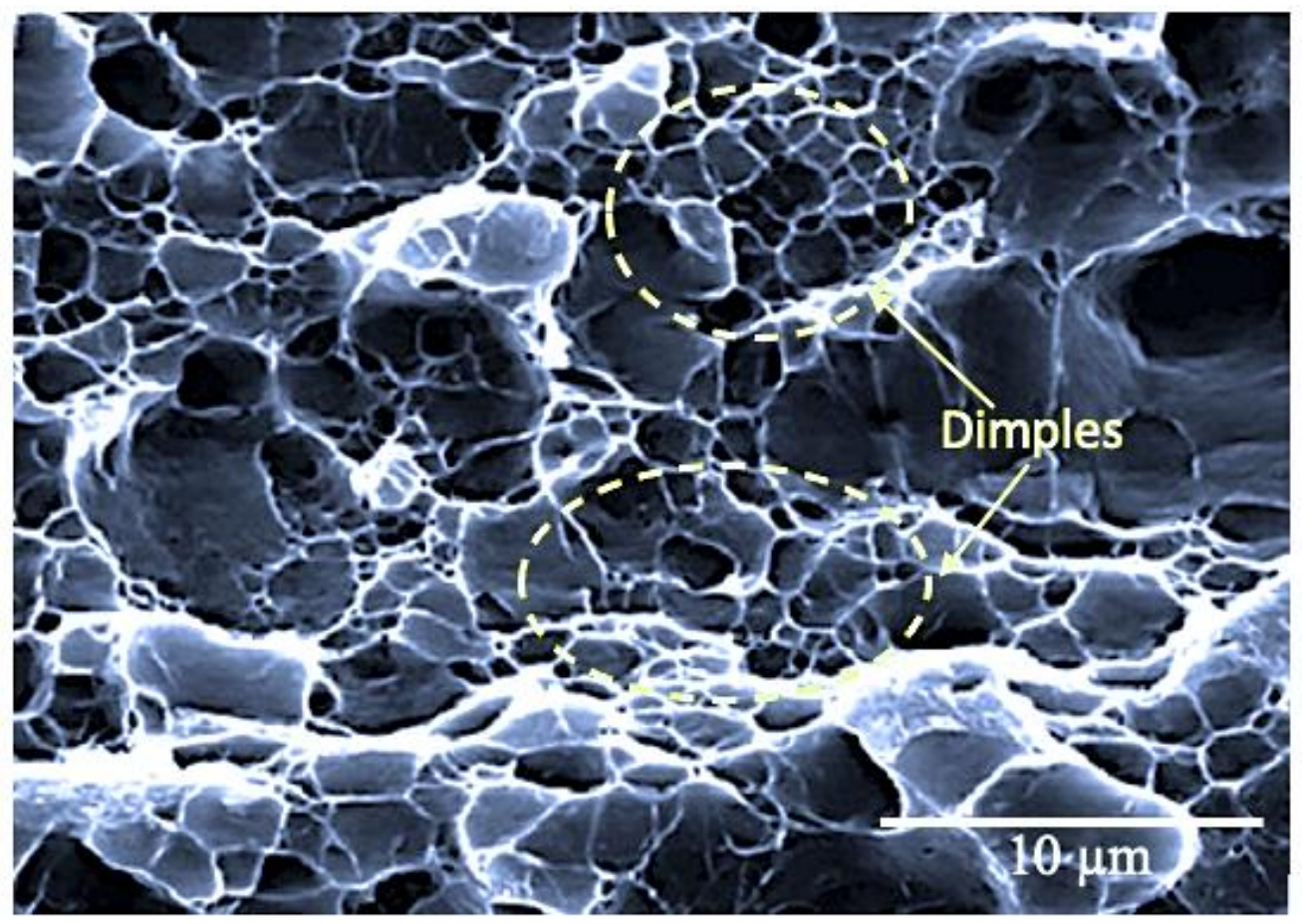

Fig. 8. Fractography of IAFSW tensile specimen

As shown in Figure 8, due to ductile fracture mode, the entire crack is propagated. Dimples and some sort of little cleavage fracture face are visible in the fractography. This slight cleavage fracture is entitled to the locally brittle fracture and rarely by the plastic deformation.

Figure 9 shows the Vickers microhardness profiles tested along the cross-section of the second IAFSW specimen at base metals (BM), heat affected zone (HAZ), thermomechanical affected zone (TMAZ) and stir zone (SZ). The same approach was taken by researchers previously to find the FSW specimens' microhardness profile [24].

The advancing side of the SZ where X12Cr13 SS is placed shows a higher microhardness, which is around $307 \mathrm{HV}$ on average. This higher hardness results from partial annealing in that region by induction heating and frictional heat generated by the IAFSW tool. The HAZ exhibits an average microhardness of $82 \mathrm{HV}$, and this value is less compared to the BM and TMAZ [25]. Besides, the thermomechanical affected zone (TMAZ) in the AA5052 exhibits lesser microhardness than the heat-affected zone and base metal; this is because of the coarse grains and second phase particle disintegration by the heat generated in TMAZ. This heat generated in TMAZ resulted in recrystallization and dynamic recovery. 


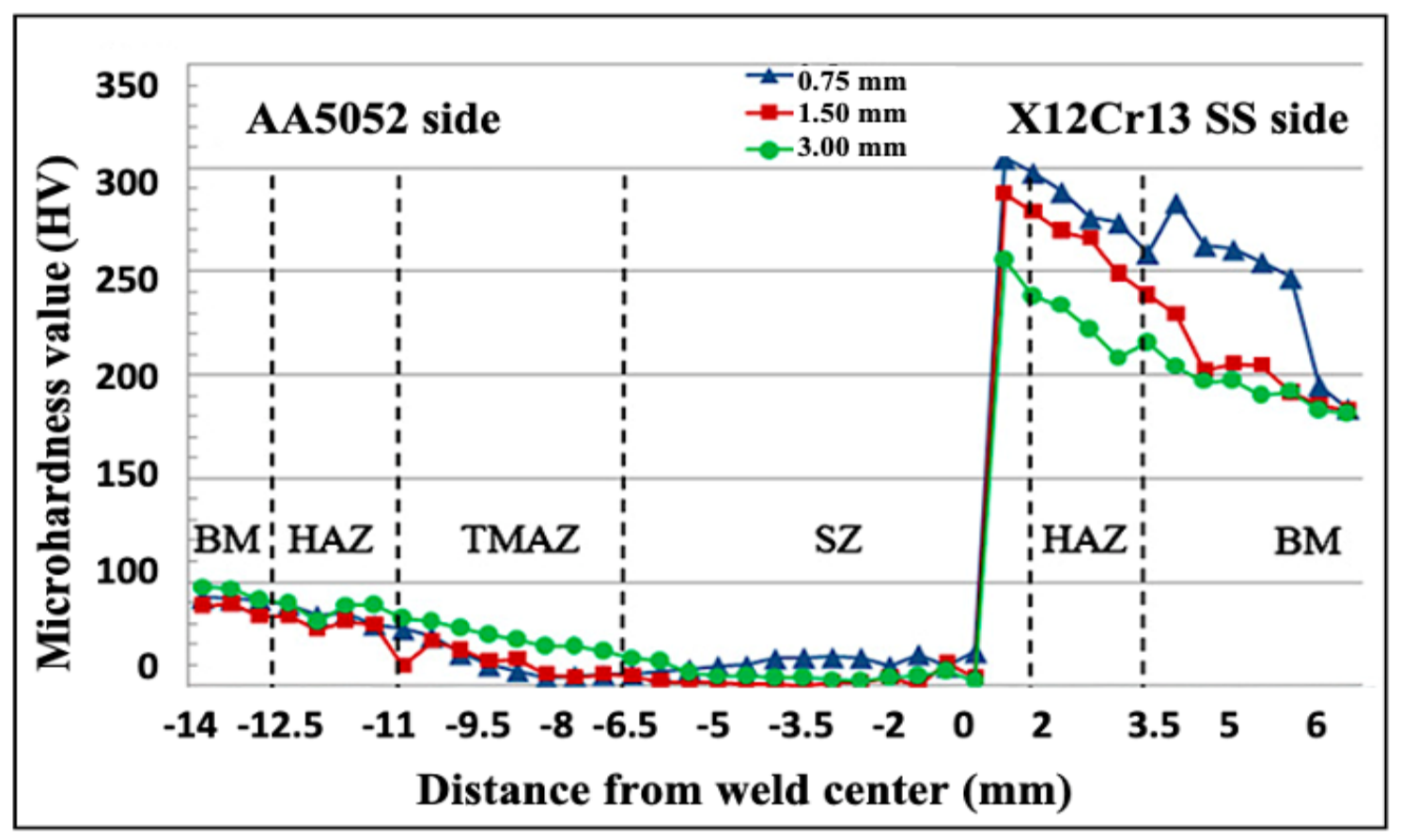

Fig. 9. Vickers microhardness profile for IAFSW specimens

Nevertheless, the average microhardness at the stir zone is around $47 \mathrm{HV}$, which is the least microhardness gained area, and it is lower than the AA5052. The least microhardness gained region is about $0-6.5 \mathrm{~mm}$ from the nugget centre [26-28]. The reduction in microhardness in the SZ is caused by the disbanding of precipitates, and precipitative behaviour happed to the AA5052 in the nugget zone while joining. Meanwhile, compared to the SZ, the microhardness in the HAZ and TMAZ in the X12Cr13 SS region were enhanced due to the work hardening $[29,30]$.

\section{Microstructure characterization for IAFSW specimens}

Figure 10 shows the micrograph images for the IAFSW specimen prepared at the parameters combinations of $750 \mathrm{rpm}$ tool rotation, $53 \mathrm{~mm} / \mathrm{min}$ welding speed, $0.58 \mathrm{~mm}$ plunge depth, $55 \mathrm{~W}$ induction power and a standoff distance $35 \mathrm{~mm}$.

Figure 10a shows the microstructure image of the TMAZ region of the AA5052, (b) shows the microstructure image of the nugget zone of the weldment and (c) shows the microstructure image of X12Cr13 SS TMAZ regions, respectively. The grain structure of AA5052 at the TMAZ region shows a slightly fine grain structure [31,32]. It is elongated inversely to the rolling direction of the base metal due to the in-situ heating, the plasticization and plunging force delivered by the tool pin and shoulder. The nugget zone in Figure $-10(\mathrm{~b})$ shows a composite grain structure of both the base metals. A refined and recrystallized AA5052 grains were visible in the nugget zone, and X12Cr13 SS particles speckled away from the X12Cr13 SS surface and exhibited a fully amalgamated structure at the bimetallic interface (nugget zone and stir zone) of AA5052 and X12Cr13 SS. This refined grain structure resulted from proper plasticization, and material flow happened in the weld zone, and the adequate heat generated in the butt interface by the IAFSW tool and induction heating coil [33-35]. Remarkably, in this work, the total temperature generated by both the in-situ induction heater and friction stir welding tool is around $620{ }^{\circ} \mathrm{C}$, which is appropriate for recrystallization. The grain size will be more refined than the base metal in the weld zone when the recrystallization happens by the synergic effect of in-situ heating and the IAFSW 
tool. Also, this additional in-situ heating will decrease the dislocation density as well. Therefore, the ductility of the joint interface will enhance, and there will be a slight reduction in microhardness and tensile strength.

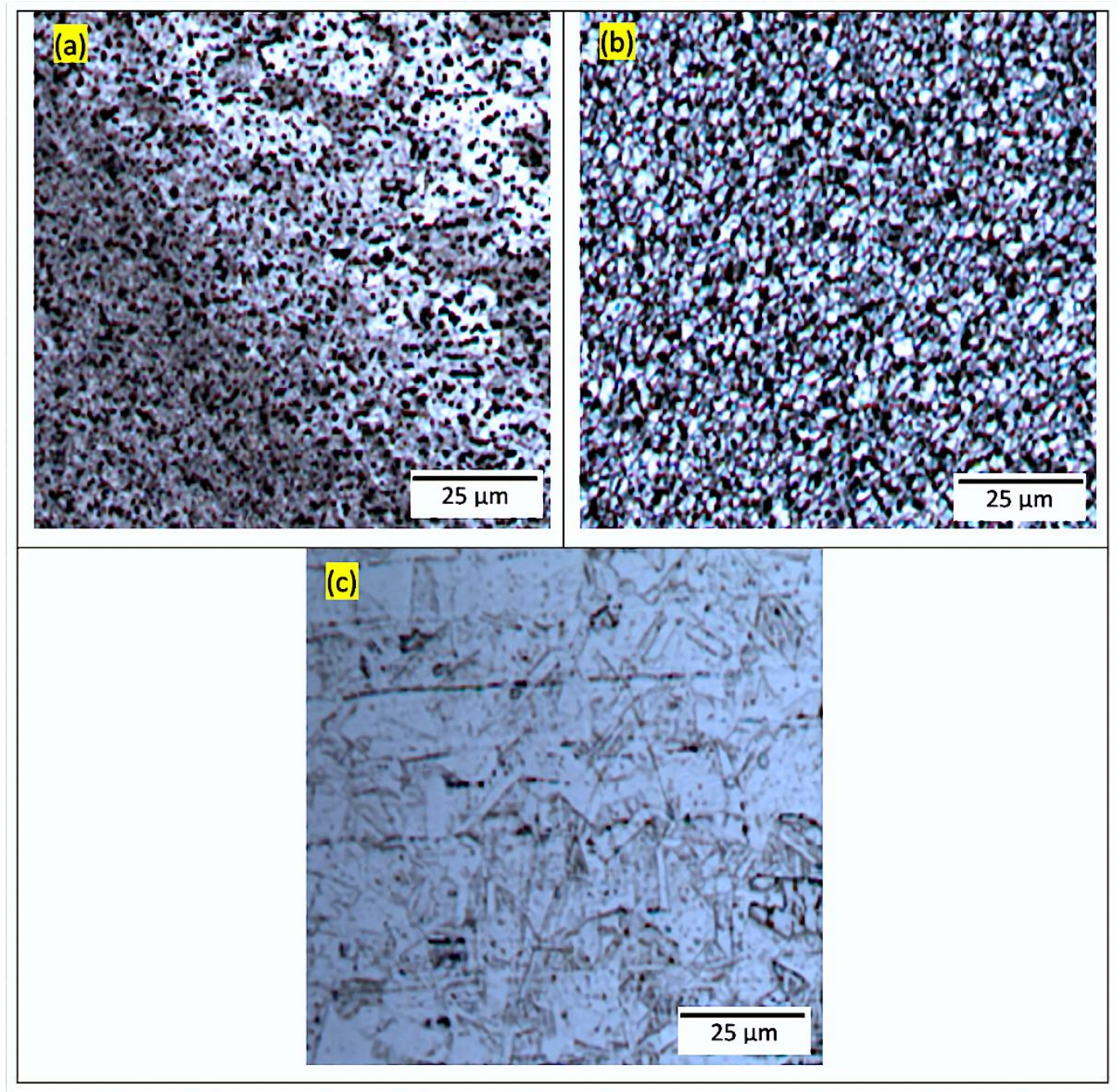

Fig. 10. (a) Micrograph image of TMAZ at AA5052 (b) Nugget zone (c) TMAZ at X12Cr13 SS

This experimentation reveals two types of material flow while examining the specimen. At first, the AS material moves into the stir zone and instantaneously moved to the retreating size with the pin; this initial movement happened by the string effect of the tool pin [36]. This plasticization happened in the metals by the induction heat and tool friction by the tool rotation (rpm), which are the reasons for this metal movement. Moreover, this plasticization enhances the fine grain formation in the nugget zone. This type of metal movement was found earlier [37,38]. On the RS region, the second metal flow was found; it is due to the shear action of the tool by welding speed $(\mathrm{mm} / \mathrm{min})$ and the extrusion of the material around the tool shoulder. The in-situ heating by the induction coil has a crucial role in this extrusion of metals in the stool shoulder region. This extrusion resulted from the plasticization of metals in the RS by the in-situ induction heating [39,40]. Apart from the in-situ heated area or tool travelled region, these material movements were not visible. 


\section{CONCLUSIONS}

Induction assisted friction stir welding of AA5052 (aluminium alloy) with X12Cr13 SS was joined successfully by employing in-situ induction heating. A defect-free joint was achieved at a tool rotation speed of $750 \mathrm{rpm}$. The summary of this experiment are as follows:

1. The higher tensile strength of $229.5 \mathrm{MPa}$ was gained by the second specimen, which is joined at a tool rotation speed of $750 \mathrm{rpm}$, welding speed of $53 \mathrm{~mm} / \mathrm{min}$, plunge depth of $0.58 \mathrm{~mm}$, induction power of $55 \mathrm{~W}$ (which produce $486{ }^{\circ} \mathrm{C}$ temperature) and a standoff distance of $35 \mathrm{~mm}$. The tensile strength gained was $94 \%$ of the AA5052 and $51 \%$ of the $\mathrm{X} 12 \mathrm{Cr} 13 \mathrm{SS}$. Fractography of the tensile specimen reveals that the fracture is wholly due to the ductile mode of fracture with dimples on the fracture surface. Some slight cleavage faces are visible on the fracture surface, resulting from the local brittle mode of fracture by plastic deformations. The experimental result shows that partial annealing has happened to the metals, and adequate materials flow is achieved due to the in-situ heating. This in-situ heating enhances the elongation and notably improves the strength of the dissimilar metals joined with AA5052 and X12Cr13 SS.

2. The stir zone of the IAFSW joint, around $0-6.5 \mathrm{~mm}$ from the nugget zone, exhibits the lowest microhardness (below 55\%) compared to the parent metal AA5052; this is because of the softening the AA5052 area by the precipitative actions that happened while joining.

3. The grain structure exhibited in the TMAZ and HAZ by the AA5052 is much refined than the X12Cr13 SS. A fine composite grain structure was visible in the nugget zone, where the AA5052 particles show a refined recrystallized structure. The in-situ induction heating and tool movements enhanced the material flow in both the AS and RS by plasticizing the intermetallic region. In contrast, the $\mathrm{X} 12 \mathrm{Cr} 13 \mathrm{SS}$ particles are disseminated from its surface and exposed to an assorted structure in the joint interface.

4. A refined grain structure was visible in the nugget zone of the joint, and these refined grains have resulted in rigorous plastic deformation in the nugget zone. This sufficient plasticization and advanced material flow were achieved by the in-situ heating of the induction heating coil and by the frictional heat produced by the IAAIFSW tool. Remarkably, the experimental results confirmed that a more refined grain structure was achieved while recrystallization happened by the in-situ heating source. The dislocation density was also reduced; this resulted in the enhancement of ductility and a slight reduction in microhardness and tensile strength.

\section{ACKNOWLEDGEMENT}

The authors acknowledge the Institute of Materials Joining, Shandong University, Jinan, China, and the China Postdoctoral Council for their immense supports. Also acknowledge the Department of Production Engineering, Government College of Technology, Coimbatore, India. 


\section{REFERENCES}

1. Mohan D G, Gopi S: Influence of In-situ induction heated friction stir welding on tensile, microhardness, corrosion resistance and microstructural properties of martensitic steel. Engineering Research Express, 3(2), 2021, 025023.

2. Janeczek A, Tomków J, Fydrych D: The influence of tool shape and process parameters on the mechanical properties of AW-3004 aluminium alloy friction stir welded joints. Materials, 14(12), $2021,3244$.

3. Abd Elnabi M M, Osman T A, El Mokadem A, Elshalakany A B: Evaluation of the formation of intermetallic compounds at the intermixing lines and in the nugget of dissimilar steel/aluminum friction stir welds. Journal of Materials Research and Technology, 9(5), 2020, 10209-10222.

4. Anaman S Y, Cho $\mathrm{H}$ H, Das H, Lee J S, Hong S T: Microstructure and mechanical/electrochemical properties of friction stir butt welded joint of dissimilar aluminum and steel alloys. Materials Characterization, 154, 2019, 67-79.

5. Wang T, Komarasamy M, Liu K, Mishra R S: Friction stir butt welding of strain-hardened aluminum alloy with high strength steel. Materials Science and Engineering A, 737, 2018, 85-89.

6. Joo S: Joining of dissimilar AZ31B magnesium alloy and SS400 mild steel by hybrid gas tungsten arc friction stir welding. Metals and Materials International, 19, 2013, 1251-1257.

7. Fei X, Jin X, Ye Y, Xiu T, Yang H: Effect of pre-hole offset on the property of the joint during laser-assisted friction stir welding of dissimilar metals steel and aluminum alloys. Materials Science and Engineering A, 653, 2016, 43-52.

8. Campanelli S L, Casalino G, Casavola C, Moramarco V: Analysis and comparison of friction stir welding and laser assisted friction stir welding of aluminum alloy. Materials, 6(12), 2013, 59235941.

9. Ma Z, Shang Q, Ni D, Xiao B: Friction Stir Welding of magnesium alloys: A review. In Jinshu Xuebao/Acta Metallurgica Sinica, 54(11), 2018, 238-253.

10. Bucior M, Kluz R, Kubit A, Ochał K: Analysis of the possibilities of improving the selected properties surface layer of butt joints made using the FSW method. Advances in Science and Technology Research Journal, 14(1), 2020, 1-9.

11. Bang H S, Jeon G H, Oh I H, Ro C S: Gas tungsten arc welding assisted hybrid friction stir welding of dissimilar materials Al6061-T6 aluminum alloy and STS304 stainless steel. Materials and Design, 37, 2012, 48-55.

12. Sasikumar A, Gopi S, Mohan D G: Effect of magnesium and chromium fillers on the microstructure and tensile strength of friction stir welded dissimilar aluminium alloys. Materials Research Express, 6(8), 2019, 086580.

13. Kravcov A, Kosturek R, Śnieżek L, Kluczyński J, Franek O, Morozov N, Maciejewski P: The influence of friction stir welded process parameters of AA2519-T62 on joint quality defined by non-destructive laser amplified ultrasonic method and by microstructure analysis. Acta Polytechnica 60(5), 2020, 415-19.

14. Gopi S, Mohan D G: Evaluating the welding pulses of various tool profiles in single-pass Friction Stir Welding of 6082-T6 aluminium alloy. Journal of Welding and Joining, 2232, 2021, 1-11.

15. Dehghani M, Akbari Mousavi S A A, Amadeh A: Effects of welding parameters and tool geometry on properties of 3003-H18 aluminum alloy to mild steel friction stir weld. Transactions of Nonferrous Metals Society of China, 23, 2013, 1957-1965.

16. Sasikumar A, Gopi S, Mohan D G: Effect of welding speed on mechanical properties and corrosion resistance rates of filler induced friction stir welded AA6082 and AA5052 joints. Materials Research Express, 8(6), 2021, 066531. 
17. Mohan D G, Gopi S: Optimized parameters prediction for single-pass Friction Stir Welding on dissimilar aluminium alloys T-joint. International Journal of Emerging Technologies, 12(2), 2021, 22-27.

18. Makeshkumar M, Surender S R, Arunprakash S, Madesh R, Sasi Kumar M, Sudharsan K: Microstructural and mechanical properties evaluation of dissimilar aluminum alloy and bronze joints using friction stir welding, Materials Today: Proceedings, 8, 2021, 4-21.

19. Mohan D G, Gopi S: Induction assisted friction stir welding: a review, Australian Journal of Mechanical Engineering, 18:1, 2020, 119-123.

20. Kosturek R, Śnieżek L, Torzewski J, Ślęzak T, Wachowski M, Szachogłuchowicz I: Research on the properties and low cycle fatigue of Sc-modified AA2519-T62 FSW joint. Materials, 13(22), 2020, 2-18.

21. Mohan D G, Gopi S, Rajasekar V: Effect of induction heated friction stir welding on corrosive behaviour, mechanical properties and microstructure of AISI 410 stainless steel. Indian Journal of Engineering and Materials Sciences, 2(1), 2018, 203-208.

22. Florence P L, Narayanaswamy K S, Sesha P H, Sai T, Devaraj S: Impact of friction stir welding tool profile on the strength of dissimilar aluminium and stainless steel welded joints. Materials Today: Proceedings 8(2), 2021, 1127-1136.

23. Kravcova A, Kosturek R, Śnieżek L, Kluczyński J, Franek O, Morozov N, Maciejewski P: The influence of friction stir welded process parameters of AA2519-T62 on joint quality defined by non-destructive laser amplified ultrasonic method and by microstructure analysis. Acta Polytechnica 60(5), 2020, 415-419.

24. Tamadon A, Pons D J., Sued K and Clucas D: Internal flow behaviour and microstructural evolution of the Bobbin-FSW welds: thermomechanical comparison between 1 xxx and 3xxx aluminium grades. Advances in Materials Science, 21(2), 2021, 40-64.

25. Mohan DG, Gopi S: Study on the mechanical behaviour of friction stir welded aluminium alloys 6061 with 5052. $20178^{\text {th }}$ Industrial Automation and Electromechanical Engineering Conference, IEMECON, 2017, 147-152.

26. Padhy G K, Wu C S, Gao S: Friction stir based welding and processing technologies - processes, parameters, microstructures and applications. A review. Journal of Materials Science \& Technology, 34(1), 2018, 1-38.

27. Mohan D G, Gopi S, Sasikumar A: Examining the mechanical and metallurgical properties of single pass friction stir welded dissimilar aluminium alloys tee joints, SVOA Materials Science \&Technology, 3(1), 2021, 6-12.

28. Wang W, Deng D, Mao Z, Tong Y, Ran Y: Influence of tool rotation rates on temperature profiles and mechanical properties of friction stir welded AZ31 magnesium alloy. International Journal of Advanced Manufacturing Technology, 88, 2017, 2191-2200.

29. Mohan D G, Gopi S: A Review on friction stir welded T-joint. IJSTE - International Journal of Science Technology \& Engineering, 2(07), 2016, 40-45.

30. Dong H, Yang J, Li Y, Xia Y, Hao X, Li P, Sun D, Hu J, Zhou W, Lei M: Evolution of interface and tensile properties in 5052 aluminum alloy/304 stainless steel rotary friction welded joint after post-weld heat treatment. Journal of Manufacturing Processes. 51, 2020, 142-150.

31. Mohan D G, Gopi S, Rajasekar V: Mechanical and corrosion-resistant properties of hybridwelded stainless steel. Materials Performance, 57(1), 2018, 53-56.

32. Yang J, Hu A, Li Y, Zhang P, Chandra Saha D, Yu Z: Heat input, intermetallic compounds and mechanical properties of $\mathrm{Al} / \mathrm{steel}$ cold metal transfer joints. Journal of Materials Processing Technology, 272, 2019, 40-46. 
33. Kimura M, Suzuki K, Kusaka M, Kaizu K: Effect of friction welding condition on joining phenomena, tensile strength, and bend ductility of friction welded joint between pure aluminium and AISI 304 stainless steel. Journal of Manufacturing Processes, 25, 2017, 116-125.

34. Pan L, Li P, Hao X, Zhou J, Dong H: Inhomogeneity of microstructure and mechanical properties in radial direction of aluminum/copper friction welded joints. Journal of Materials Processing Technology, 255, 2018, 308-318.

35. Dong H, Li Y, Li P, Hao X, Xia Y, Yang G: Inhomogeneous microstructure and mechanical properties of rotary friction welded joints between 5052 aluminum alloy and 304 stainless steel. Journal of Materials Processing Technology, 272, 2019, 17-27.

36. Jagadeesha C: Flow analysis of materials in friction stir welding. Journal of the Mechanical Behavior of Materials, 27(3-4), 2018, 20180020.

37. Zhai $\mathrm{M}, \mathrm{Wu} \mathrm{C}, \mathrm{Su} \mathrm{H}$ : Influence of tool tilt angle on heat transfer and material flow in friction stir welding. Journal of Manufacturing Processes, 59, 2020, 98-112.

38. Chen S, Han Y, Jiang X, Li X, Yuan T, Jiang W, Wang X: Study on in-situ material flow behaviour during friction stir welding via a novel material tracing technology. Journal of Materials Processing Technology, 297, 2021, 117205.

39. Memon S, Tomków J, Derazkola H A: Thermo-mechanical simulation underwater friction stir welding of low carbon steel. Materials, 2021, 14(17), 2021, 4953.

40. Memon S, Fydrych D, Fernandez A C, Derazkola H A, Derazkola H A: Effects of FSW tool plunge depth on properties of an Al-Mg-Si alloy $\mathrm{T}$-joint: Thermomechanical modeling and experimental evaluation. Materials, 14(16), 2021, 4754. 